\title{
Synthesis and in Vitro Evaluation of Stabilized and Selective Neuromedin U-1 Receptor Agonists
}

An De Prins, ${ }^{\dagger \dagger}$ Charlotte Martin, ${ }^{\dagger}$ Yannick Van Wanseele, ${ }^{\dagger}$ Csaba Tömböly, ${ }^{\S}$ Dirk Tourwé, ${ }^{\dagger}$ Vicky Caveliers, ${ }^{\|, \perp}$ Birgitte Holst, ${ }^{\nabla}$ Ann Van Eeckhaut, ${ }^{\ddagger}$ Mette M. Rosenkilde, ${ }^{*}, \nabla$ Ilse Smolders, ${ }^{*}{ }^{\ddagger}$ and Steven Ballet* ${ }^{* \dagger}$ (i)

${ }^{\dagger}$ Research Group of Organic Chemistry, Departments of Chemistry and Bioengineering Sciences, Vrije Universiteit Brussel, Pleinlaan 2, 1050 Brussels, Belgium

${ }^{\ddagger}$ Department of Pharmaceutical Chemistry, Drug Analysis and Drug Information, Center for Neurosciences, Vrije Universiteit Brussel, Laarbeeklaan 103, 1090 Brussels, Belgium

${ }^{\S}$ Biological Research Centre, Institute of Biochemistry, Laboratory of Chemical Biology, 6726 Szeged, Temesvári krt. 62, Hungary

"In Vivo Cellular and Molecular Imaging Laboratory, Vrije Universiteit Brussel, Laarbeeklaan 103, 1090 Brussels, Belgium

${ }^{\perp}$ Department of Nuclear Medicine, UZ Brussel, Laarbeeklaan 101, 1090 Brussels, Belgium

${ }^{\nabla}$ Laboratory for Molecular Pharmacology, Department of Biomedical Sciences, Faculty of Health and Medical Sciences, University of Copenhagen, Blegdamsvej 3, 2200 Copenhagen, Denmark

\section{Supporting Information}

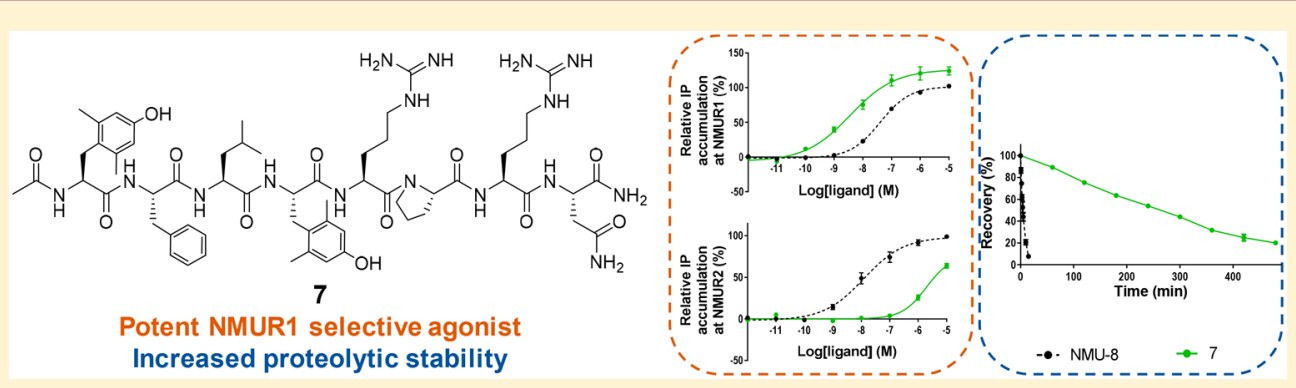

ABSTRACT: Neuromedin U (NMU) is a multifunctional neuropeptide which is characterized by a high conservation through all species. Herein, we describe the synthesis of a novel set of NMU-analogs based on the truncated NMU-8. Through combination of previously reported modifications, an elaborate structure-activity relationship study was performed aiming for the development of peptides with an increased selectivity toward NMU receptor 1 (NMUR1). Compound 7 possessed the highest NMUR1 selectivity $\left(\mathrm{IC}_{50}=0.54 \mathrm{nM}\right.$, selectivity ratio $\left.=5313\right)$ together with an increased potency $\left(\mathrm{EC}_{50}=3.7 \mathrm{nM}\right)$, an $18 \%$ increase of the maximal effect at NMUR1, and a higher resistance against enzymatic degradation as compared to the native NMU-8. The development of a potent NMUR1 agonist with extended half-life could represent an attractive tool to further unveil the role of NMUR1 in NMU signaling.

KEYWORDS: Neuromedin U (NMU), NMU-8, Neuromedin U receptor agonist, NMUR1, in vitro plasma stability

$\mathrm{N}$ euromedin $\mathrm{U}(\mathrm{NMU})$ is a highly conserved neuropeptide which occurs in two main isoforms, a 23 to 25 amino acid long peptide, and in certain species a truncated version of 8 or 9 amino acids is present and considered to be a degradation product from the larger peptide. The highest homology between variants in different species is found at the $C$-terminus of the NMU peptide with the $C$-terminal heptapeptide (-PheLeu-Phe-Arg-Pro-Arg-Asn- $\mathrm{NH}_{2}$ ) being entirely conserved in mammalian species. ${ }^{1}$ NMU exerts its biological effects through two G protein-coupled receptors (GPCRs), more precisely neuromedin $U$ receptor 1 (NMUR1) and NMUR2. These receptors have a complementary tissue distribution since NMUR1 is most abundant in the periphery whereas NMUR2 is predominantly found in the central nervous system. ${ }^{1,2} \mathrm{NMU}$ is involved in various physiological processes including smooth muscle contraction, blood pressure control, regulation of the stress response, nociception, immune regulation, and suppression of feeding behavior. ${ }^{1}$ In the search for novel treatments in the field of obesity and diabetes, NMU is gaining interest since it is reported to exert anorexigenic effects and possess beneficial effects on glucose tolerance, ${ }^{3}$ which resulted in extensive structure-activity relationship (SAR) studies and the development of different potent and long acting NMU-analogs. ${ }^{4-10}$ To date, several promising agonists for the NMURs are described, such as PEGylated NMU-25 $5^{8}$ and NMU- $8^{10,11}$ analogs, a

Received: March 3, 2018

Accepted: April 23, 2018

Published: April 23, 2018 


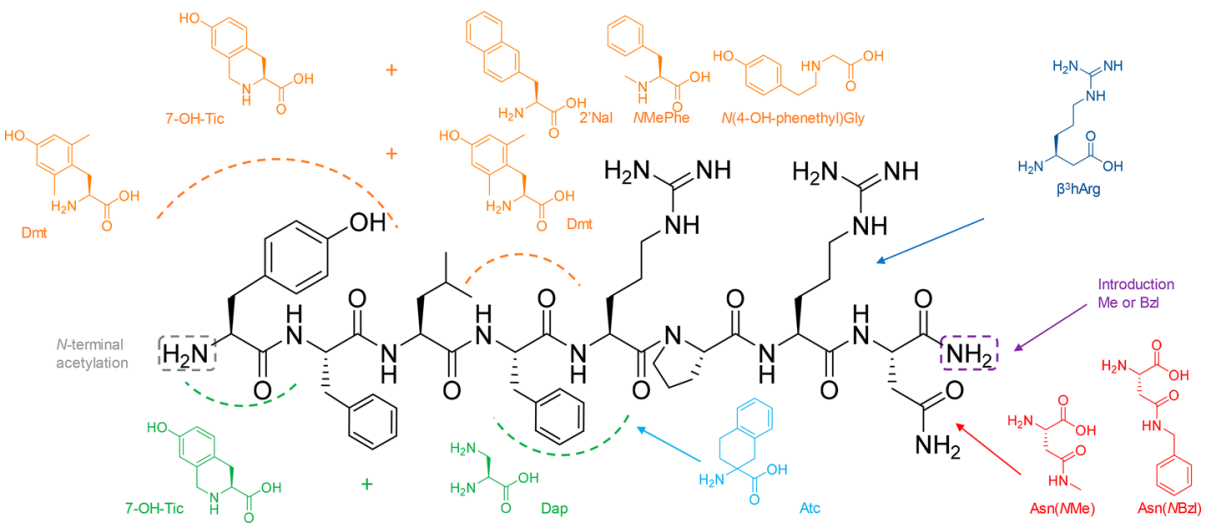

Figure 1. Structures of the NMU-8 peptide (black) and the modifications introduced into the sequence.

NMU-human serum albumin conjugate, ${ }^{9}$ lipidated NMUanalogs, ${ }^{7,6}$ and an alkylated NMU-analog, ${ }^{12}$ and all are reported to have potent and long-lasting effects on food intake. Selective agonists toward NMUR1 and NMUR2 were lately synthesized as well (e.g., 2-thienylacetyl-Trp-( $\alpha \mathrm{Me}) \operatorname{Trp}$-Arg-Pro-Arg-Asn$\mathrm{NH}_{2}{ }^{5}$ and 3-cyclohexylpropionyl-Leu-Leu-Dap-Pro-Arg-Asn$\mathrm{NH}_{2}{ }^{4}$, respectively). Recently our group performed a SAR study, with the native NMU-8 sequence (H-Tyr ${ }^{1}-\mathrm{Phe}^{2}-\mathrm{Leu}^{3}$ $\mathrm{Phe}^{4}-\mathrm{Arg}^{5}-\mathrm{Pro}^{6}-\mathrm{Arg}^{7}-\mathrm{Asn}^{8}-\mathrm{NH}_{2}$ ) as starting point and using human embryonic kidney 293 (HEK293) cells expressing the NMURs for screening. Our study revealed that acetylation of the $\mathrm{N}$-terminus results in peptides with a higher potency and plasma stability, as compared to the nonacetylated analog. Second, replacement of the Tyr residue in position 1 by 7 hydroxy-L-1,2,3,4-tetrahydroisoquinoline-3-carboxylic acid (7$\mathrm{OH}-\mathrm{Tic}), 2^{\prime}$-naphtylalanine $\left(2^{\prime} \mathrm{Nal}\right)$, or $2^{\prime}, 6^{\prime}$-dimethyltyrosine (Dmt) resulted in potent NMU-8 analogs. NMUR1 selectivity could be obtained by modification of the $\mathrm{Phe}^{4}$ residue whereas selectivity toward NMUR2 was observed when $\mathrm{Pro}^{6}$ was modified. Finally, an increased resistance against proteolytic degradation was found for all molecules tested, as compared to NMU-8. ${ }^{13}$

In this Letter we report the synthesis and in vitro biological evaluation of a novel set of NMU-8 analogs, in which novel modifications were introduced, but also promising modifications of our previous findings were combined, with the aim to develop molecules with improved pharmacological profiles (Figure 1). The novel NMU-analogs were synthesized manually as reported before via conventional Fmoc-based solid phase peptide synthesis using Rink Amide AM resin as a solid support and 2-(1H-benzotriazole-1-yl)-1,1,3,3-tetramethylaminium tetrafluoroborate (TBTU)/N,N-diisopropylethylamine (DIPEA) as coupling mixture (see Supporting Information). ${ }^{13} \mathrm{~N}$ Substituted glycines (the so-called "peptoid" residues) were synthesized following the solid phase submonomer method. ${ }^{14}$ After complete deprotection and cleavage from the resin with trifluoroacetic acid (TFA)/triethylsilane (TES)/water (95/2.5/ $2.5 \mathrm{v} / \mathrm{v} / \mathrm{v})$, purification of the peptides was performed by preparative high-performance liquid chromatography (HPLC), using a water-acetonitrile gradient system containing $0.1 \%$ TFA. All NMU-analogs had a purity greater than $95 \%$ as assessed by HPLC analysis, and their structure was confirmed by high resolution mass spectrometry (HRMS) (see Supporting Information, Table S1). Tritiated NMU-8, which was used for the binding studies, was obtained as described before (see Supporting Information for experimental details). ${ }^{13}$ Evaluation of the affinities and agonistic activities of the NMU-analogs at the NMURs was performed in the present study on HEK293 cells transiently expressing human (h)NMUR1 and hNMUR2 as reported before. ${ }^{13}$ Evaluation of the affinity of the novel NMU-analogs for the NMURs was performed with a competitive binding assay using $\left[{ }^{3} \mathrm{H}\right]-\mathrm{NMU}-8$ as radioligand. An inositol triphosphate $\left(\mathrm{IP}_{3}\right)$ accumulation assay was carried out to study the functional activity of the NMU-analogs. All analogs were tested in at least 3 independent experiments using triplicates in a concentration range of $10^{-5}$ to $10^{-11} \mathrm{M}$. Table 1 shows the results for the novel NMU-analogs.

Since previous SAR data revealed that $N$-terminal acetylation of NMU results in peptides with an increased potency and proteolytic stability, the current letter reports only acetylated NMU-analogs. Several studies state the $C$-terminal part of the sequence, more precisely -Pro-Arg-Asn- $\mathrm{NH}_{2}$, to be the core structure necessary for activation of the NMURs. ${ }^{4}$ Interestingly, we successfully modified this critical region by modification of the Pro $^{6}$ residue and found that modification of this residue could lead to selectivity toward NMUR2. ${ }^{13}$ In the current study, this critical and conserved region was further explored. In a first step, $\mathrm{Arg}^{7}$ was replaced by the homologated $\beta^{3}$ homoArg $\left(\beta^{3} \mathrm{hArg}\right.$ ) (to give compound 1, Ac-Tyr-Phe-Leu-Phe-Arg-Pro$\left.\boldsymbol{\beta}^{3} \mathbf{h A r g}-\mathrm{Asn}-\mathrm{NH}_{2}\right)$. This NMU-analog displayed decreased affinity for both NMURs $\left(\mathrm{IC}_{50}=28.1 \mathrm{nM}\right.$ and $116.5 \mathrm{nM}$ for NMUR1 and NMUR2, respectively). Additionally, it proved to be a full agonist at NMUR1 with a 4-fold reduction in potency in comparison with NMU-8. Compound $\mathbf{1}$ only partially activated NMUR2 with an $\mathrm{EC}_{50}$ value (i.e., $55.6 \mathrm{nM}$ ) in the range of the potency reported for NMU-8. When analog 1 was compared with Ac-NMU-8, lower affinities and potencies for both NMURs were found. By insertion of $\beta$-homoamino acids, the backbone is elongated by one carbon atom, in this case between the $\mathrm{Arg}^{7}$ and $\mathrm{Asn}^{8}$ residues. This shift might have caused an unfavorable projection of the side chains of these residues, eventually leading to a loss in binding to the NMURs. Although it was reported that the C-terminal $\mathrm{Asn}^{8}$ is essential for NMUR activation, we modified this residue in two different manners: (i) by the introduction of a methyl or benzyl group in the side chain amide of Asn and (ii) by modification of the $C$ terminal amide. The addition of a methyl group in the side chain amide of $\mathrm{Asn}^{8}$ (to present compound 2, Ac-Tyr-Phe-LeuPhe-Arg-Pro-Arg-Asn (NMe)- $\mathrm{NH}_{2}$ ) caused a more than 10-fold decreased affinity for the NMURs, when compared to NMU-8 and Ac-NMU-8, but a preserved potency as compared to the native NMU-8 peptide was found. Analog 3, in which a benzyl amide was present in the side chain of $\mathrm{Asn}^{8}$ (i.e, Ac-Tyr-PheLeu-Phe-Arg-Pro-Arg-Asn( $\left.\mathbf{N B z l})-\mathrm{NH}_{2}\right)$, possessed a NMU-8- 
Table 1. In Vitro Affinity and Activity of the NMU-Analogs at hNMUR1 and hNMUR2

\begin{tabular}{|c|c|c|c|c|c|c|c|}
\hline \multirow{3}{*}{ Compound } & \multicolumn{3}{|c|}{ hNMUR1 } & \multicolumn{3}{|c|}{ hNMUR2 } & \multirow{3}{*}{$\begin{array}{c}\text { Selectivity }^{d} \\
\mathrm{IC}_{50} \text { NMUR2/ } \\
\mathrm{IC}_{50} \text { NMUR1 }\end{array}$} \\
\hline & \multirow{2}{*}{$\begin{array}{c}\text { Affinity } \\
\mathrm{IC}_{50}(\mathrm{nM})^{a}\end{array}$} & \multicolumn{2}{|c|}{ Potency } & \multirow{2}{*}{$\begin{array}{c}\text { Affinity } \\
\mathrm{IC}_{50}(\mathrm{nM})\end{array}$} & \multicolumn{2}{|c|}{ Potency } & \\
\hline & & $\mathrm{EC}_{50}(\mathrm{nM})^{b}$ & $E_{\max }(\%)^{c}$ & & $\mathrm{EC}_{50}(\mathrm{nM})$ & $E_{\max }(\%)$ & \\
\hline NMU-8 & 0.78 & 38.9 & 100.0 & 1.7 & 30.8 & 100.0 & 2 \\
\hline Ac-NMU-8 & 0.29 & 0.51 & 111.3 & 2.0 & 0.71 & 100.0 & 7 \\
\hline 1 & 28.1 & 155.7 & 113.2 & 116.5 & 55.6 & 81.4 & 4 \\
\hline 2 & 8.2 & 57.2 & 118.1 & 29.1 & 51.2 & 85.1 & 4 \\
\hline 3 & 0.75 & 10.9 & 93.8 & 18.8 & 28.6 & 65.8 & 25 \\
\hline 4 & 21.3 & 843.0 & 118.8 & 327.5 & 440.8 & 106.8 & 15 \\
\hline 5 & 37.0 & 1314 & 114.8 & 28.8 & 354.2 & 103.9 & 0.8 \\
\hline 6 & 8.8 & 28.5 & 106.9 & 40.4 & 3.8 & 91.4 & 5 \\
\hline 7 & 0.54 & 3.7 & 118.1 & 2869 & 1993 & 83.2 & 5313 \\
\hline 8 & 0.092 & 2.9 & 111.8 & 301.9 & 459.3 & 100.3 & 3282 \\
\hline 9 & 350.1 & 1028 & 64.0 & 598.9 & 2205 & 91.1 & 2 \\
\hline 10 & 3.0 & 18.9 & 127.7 & 465.5 & 925.2 & 97.2 & 155 \\
\hline 11 & 2.4 & 53.3 & 99.0 & 72.4 & 59.7 & 97.6 & 30 \\
\hline
\end{tabular}

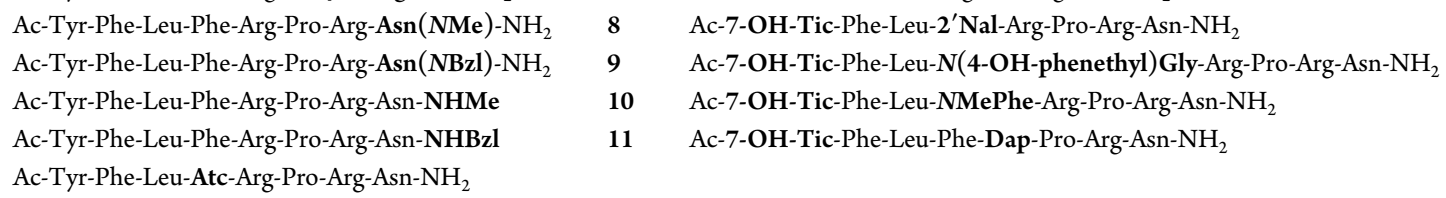

${ }^{a}$ The affinity ( $\mathrm{IC}_{50}$ value) is calculated based on the competitive binding assay with $\left[{ }^{3} \mathrm{H}\right]$-NMU-8 as radioligand (Supporting Information, Table S2, for $\mathrm{K}_{\mathrm{i}}$ values). ${ }^{b}$ The potency $\left(\mathrm{EC}_{50}\right.$ value) is calculated based on the $\mathrm{IP}_{3}$ accumulation assay. ${ }^{c} E_{\max }$ is the percentage of the maximum response at $10^{-5}$ M compared with the NMU-8 response at the same concentration. ${ }^{d}$ Receptor selectivity is expressed as the ratio of the IC ${ }_{50}$ value for NMUR2 over the $\mathrm{IC}_{50}$ value for NMUR1 of each analog. Sequences are shown in the bottom portion of the table, and modifications are marked in bold.

like potency at NMUR1 in combination with a subnanomolar affinity. At NMUR2, this peptide was a partial agonist $\left(E_{\max }=\right.$ $65.8 \%$ ) with a decreased receptor affinity. Next, we also modified the $C$-terminal amide. When a methyl or a benzyl group was inserted, to present compounds 4 (Ac-Tyr-Phe-LeuPhe-Arg-Pro-Arg-Asn-NHMe) and 5 (Ac-Tyr-Phe-Leu-PheArg-Pro-Arg-Asn-NHBzl), respectively, weak agonists with a decreased affinity at both receptors were found. The loss in receptor binding and activation indicates that the $C$-terminal amidation not only is a natural protection mechanism against carboxypeptidase driven degradation ${ }^{15}$ but plays as well an important role in the NMUR binding and activation. Hence, we demonstrated that it is possible to modify the $C$-terminal region of the NMU-8. The substitution of $\operatorname{Arg}^{7}$ by $\beta^{3}$ hArg resulted in a peptide which was still able to bind to the NMURs, although with a lower affinity as compared to NMU-8, yet substantial receptor activation was found. Modification of the Asn residue also gave rise to full agonists for NMUR1 which were able to activate the NMUR2 as well, though only partially.

Our previous SAR study revealed that substitution of $\mathrm{Phe}^{4}$ by unnatural Phe- and Tyr-analogs served as a tool to obtain potent NMU-peptides with an increased NMUR1 selectivity and improved plasma stability. ${ }^{13}$ Here, we report the synthesis of a NMU-analog in which $\mathrm{Phe}^{4}$ was replaced by $(\mathrm{D}, \mathrm{L})-2$ aminotetralin (Atc), resulting in compound 6 (Ac-Tyr-PheLeu-Atc-Arg-Pro-Arg-Asn- $\mathrm{NH}_{2}$ ). Due to peak overlay in the HPLC analysis, the resulting diastereomers were inseparable and tested as a mixture. The introduction of Atc induced only a small selectivity shift toward NMUR1, with a selectivity ratio $\left(\mathrm{IC}_{50} \mathrm{NMUR2} / \mathrm{IC}_{50} \mathrm{NMUR} 1\right)$ of 4.6. Analog 6 possessed similar potencies at the NMURs as compared to NMU-8 with a slightly better NMUR2 potency. However, it did not reach the levels reported for the Ac-NMU-8 potency. Neither selectivity toward NMUR1 nor the subnanomolar affinity for this receptor was observed for compound 6. A possible explanation can be the negative influence of the introduced Atc on the backbone folding, since $\alpha, \alpha$-dialkylated amino acids are known to induce turn/helix conformations. Moreover, the aromatic moiety of the Atc residue could be positioned/stabilized differently, as compared to the one of $7-\mathrm{OH}-\mathrm{Tic}, 1^{\prime} \mathrm{Nal}, 2^{\prime} \mathrm{Nal}$, or Dmt. The Atc residue stabilizes the gauche $(-)$ or trans with dihedral $\chi_{1}$ angles of $-60^{\circ}$ and $180^{\circ}$, respectively, over the $\mathrm{C}_{\alpha}-\mathrm{C}_{\beta}$ bond (in the case of $(S)$-Atc). ${ }^{16,17}$ Next, we synthesized a series of peptides in which promising modifications were combined. With the aim to develop a NMUR1 selective agonist with increased potency and resistance against biodegradation, compound 7 was synthesized in which both $\mathrm{Tyr}^{1}$ and $\mathrm{Phe}^{4}$ were replaced by Dmt (Ac-Dmt-Phe-Leu-Dmt-Arg-Pro-ArgAsn- $\mathrm{NH}_{2}$ ). An increased selectivity toward NMUR1 was found for 7, which was of the same magnitude as reported for Ac[Dmt ${ }^{4}$-NMU-8 (selectivity ratio of 5313 and 5158 for compound 7 and Ac-[Dmt $\left.{ }^{4}\right]-\mathrm{NMU}-8$ respectively). ${ }^{13}$ Moreover, NMUR1 affinity and potency were in line with the ones found for the nonselective Ac-[Dmt $\left.{ }^{1}\right]-\mathrm{NMU}-8$, more precisely a subnanomolar affinity in combination with an approximately 10-fold increased activity at NMUR1, compared to NMU-8. Gratifyingly, the combination of the previously reported modifications to the NMU sequence (i.e., potency of Ac$\left[\mathrm{Dmt}^{1}\right]$-NMU-8 and selectivity of Ac-[Dmt $\left.\left.{ }^{4}\right]-\mathrm{NMU}-8\right)$ culminated to the in vitro characteristics of the potent and selective analog 7. With the same goal in mind, Tyr in position 1 was replaced by the conformationally constrained $7-\mathrm{OH}-\mathrm{Tic}$ together with the introduction of the bulky $2^{\prime} \mathrm{Nal}$ in position 4 to present compound 8 (Ac-7-OH-Tic-Phe-Leu-2' Nal-ArgPro-Arg-Asn- $\mathrm{NH}_{2}$ ). Again, a cumulative effect of the modifications was found, resulting in a NMU-analog with a 
similar affinity and potency at NMUR1 as compared to Ac-[7OH-Tic ${ }^{1}$-NMU-8 (i.e., a subnanomolar affinity together with an increased potency compared to NMU-8), in combination with an elevated NMUR1 selectivity. An even 5-fold higher NMUR1 selectivity was observed compared to Ac- $\left[2^{\prime} \mathrm{Nal}\right]$ NMU-8 (selectivity ratio $=3282$ and 610 for compound 8 and Ac- $\left[2^{\prime} \mathrm{Nal}^{4}\right]-\mathrm{NMU}-8$, respectively), ${ }^{13}$ although the selectivity level of compound 7 was not exceeded. Our previous work revealed as well that the introduction of $N$-substituted glycines in position 4 of NMU-8 resulted in weak and partial NMURs agonists. Nonetheless, the introduction of $\mathrm{N}(4-\mathrm{OH}-$ phenethyl)Gly was able to extend plasma half-life up to $18 \mathrm{~h}$ (for NMU-8 only 4 min was found). ${ }^{13}$ With the aim to develop potent and proteolytically stable NMU- 8 analogs, the use of a peptoid residue in position 4 was combined with the replacement of $\mathrm{Tyr}^{1}$ by $7-\mathrm{OH}-\mathrm{Tic}$, which was reported to give rise to potent NMURs agonists. Surprisingly compound 9 (Ac-7-OH-TicPhe-Leu-N(4-OH-phenethyl)Gly-Arg-Pro-Arg-Asn- $\mathrm{NH}_{2}$ ) resulted in an even bigger loss in potency on both NMURs, as compared to Ac- $\left[\mathrm{N}(4-\mathrm{OH}\right.$-phenethyl $\left.) \mathrm{Gly}^{4}\right]-\mathrm{NMU}-8\left(\mathrm{EC}_{50}=\right.$ $216.6 \mathrm{nM}$ and 339.2 $\mathrm{nM}$ for NMUR1 and NMUR2 respectively). ${ }^{13}$ To verify whether the side chain is placed in an unfavorable position when peptoid residues are used or the backbone amide proton in that position is necessary for receptor interaction, an analog in which $\mathrm{Phe}^{4}$ was replaced by $\mathrm{NMePhe}$, together with the 7-OH-Tic substitution in position 1, was synthesized, to give compound 10 (Ac-7-OH-Tic-PheLeu-NMePhe-Arg-Pro-Arg-Asn- $\mathrm{NH}_{2}$ ). A loss in affinity was observed at both NMURs, though more pronounced at NMUR2. Analog 10 was a weak agonist at NMUR2. At NMUR1, it exerted full and potent agonistic properties with a $27.7 \%$ increase in the maximal effect at this receptor. These findings indicate that the side chain of the peptoid residues was in an unfavorable position for receptor binding and activation rather than the need of the backbone amide proton for interaction with the NMURs. Of note, compound 10, encompassing the $\mathrm{NMePhe}$ residue in position 4, gave rise to the highest $E_{\max }$ values, tested to date (i.e., $127.7 \%$ ), indicating that other $N$-alkylations might be worthwhile to investigate in search of selective hNMUR1 agonists. Takayama et al. described that selectivity toward NMUR2 could be obtained by substitution of $\operatorname{Arg}^{5}$ by $\alpha, \beta$-diaminopropionic acid (Dap). ${ }^{4}$ In the present study, the substitution of $\mathrm{Arg}^{5}$ by Dap was combined with the introduction of 7-OH-Tic in position 1 , aiming for the development of a potent NMUR2 receptor agonist with an elevated resistance against proteolytic degradation (Ac-7-OH-Tic-Phe-Leu-Phe-Dap-Pro-Arg-Asn$\mathrm{NH}_{2}$, compound 11). Surprisingly, analog 11 possessed a 30fold higher selectivity for NMUR1, although it was equipotent at both NMURs with $\mathrm{EC}_{50}$ values of similar magnitude as compared to NMU-8.

Overall, this set of novel NMU-analogs contains several peptides with an elevated selectivity toward NMUR1, whereas none of the compounds possessed NMUR2 selectivity. Figure 2 gives an overview of the NMU-analogs with an improved selectivity profile. Especially compound 7 is a high-affinity, potent NMUR1 agonist (Figure 2A and 2C) with no significant NMUR2 activation up to $10^{-6} \mathrm{M}$ (relative inositol phosphate accumulation of $25.7 \%$ at a concentration of $1 \mu \mathrm{M}$ ) due to a loss in receptor affinity (Figure $2 \mathrm{~B}$ and $2 \mathrm{D}$ ).

An in vitro degradation study in human plasma was performed as described before ${ }^{13}$ (see Supporting Information) to investigate the effect of the introduced modifications on the
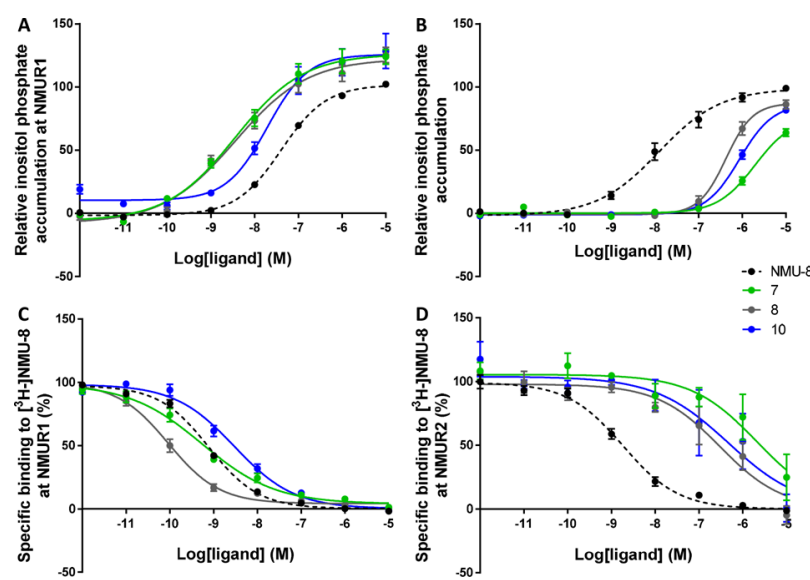

Figure 2. In vitro evaluation of NMU-analogs with increased NMUR1 selectivity. $\mathrm{IP}_{3}$ assay performed on HEK293 cells, transiently expressing (A) NMUR1 or (B) NMUR2. Affinity for NMUR1 (C) or NMUR2 (D) was evaluated in a competitive binding assay with $\left[{ }^{3} \mathrm{H}\right]$-NMU-8. For clarity, the selective compounds 3 and 11 were not shown. Data are shown as mean $\pm \operatorname{SEM}(n=3)$.

proteolytic stability of a selection of the novel NMU-analogs. The percentage of intact peptide was measured as a function of time via HPLC-UV analysis (Figure 3). To evaluate the degradation profile, samples were subsequently analyzed by LC-MS (Figure 4). NMU is characterized by a short half-life of less than $5 \mathrm{~min}$ after subcutaneous injection. ${ }^{3}$ Moreover, the plasma half-life of NMU- 8 was found to be $4.3 \pm 0.2 \mathrm{~min}$, with the neuropeptide being rapidly cleaved at its $\mathrm{N}$-terminus. $\mathrm{N}$ Terminal acetylation of NMU-8 was able to increase the resistance against proteolytic degradation, resulting in a 25 -fold longer half-life. The cleavage site after $\mathrm{Tyr}^{1}$ was protected by acetylation of the $N$-terminus, and degradation of Ac-NMU-8 occurred by cleavage between $\mathrm{Phe}^{2}-\mathrm{Leu}^{3} .^{13}$

As can intuitively be expected, modification of the $\mathrm{Arg}^{7}$ $\left(\beta^{3} \mathrm{hArg}\right.$ in 1) or $\mathrm{Asn}^{8}(\mathrm{Asn}(\mathrm{NMe})$ in $2, \mathrm{Asn}(\mathrm{NBzl})$ in 3$)$ residue, together with $N$-terminal acetylation, did not stabilize the $\mathrm{Phe}^{2}-\mathrm{Leu}^{3}$ cleavage site, and calculated half-lifes of $156.4 \pm$

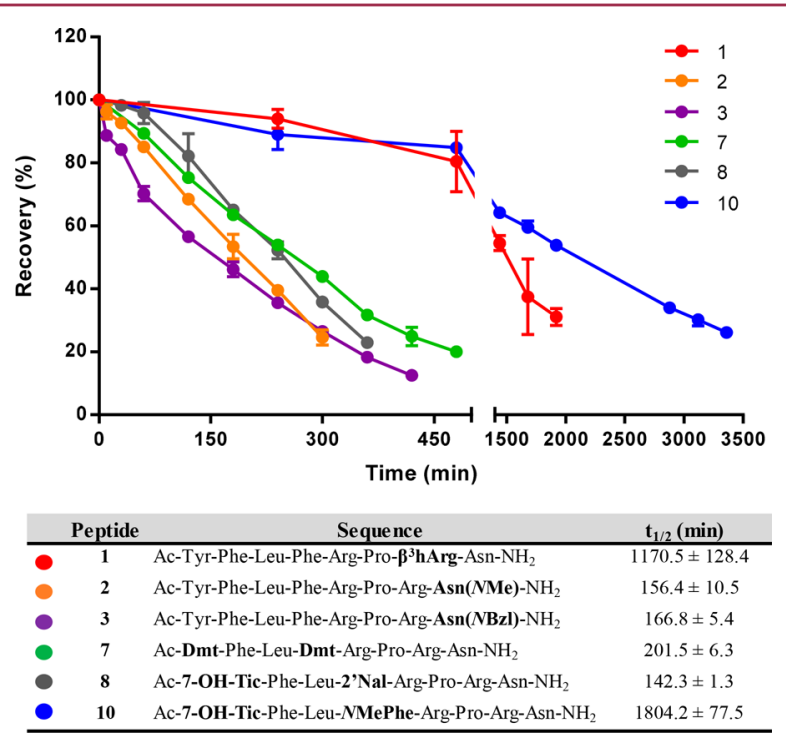

Figure 3. Relative recovery over time of the NMU-analogs in human plasma at $37{ }^{\circ} \mathrm{C}$ and calculated half-lifes. Experiments were performed in triplicate, and data are presented as mean $\pm \mathrm{SD}$. 
$10.5 \mathrm{~min}$ and $166.8 \pm 5.4 \mathrm{~min}$ were found for compounds 2 and 3, respectively. Although replacement of $\operatorname{Arg}^{7}$ by $\beta^{3}$ hArg did not alter the major cleavage site of the peptide, an extraordinary resistance against biodegradation was observed resulting in a half-life of $1170.5 \pm 128.4 \mathrm{~min}$ (or $19.5 \pm 2.1 \mathrm{~h}$ ) in human plasma for analog 1 . We previously reported that the major cleavage site of the NMU-analogs was shifted to the middle of the sequence, between $\mathrm{Phe}^{4}$ and $\mathrm{Arg}^{5}$, when $\mathrm{Tyr}^{1}$ was substituted by 7-OH-Tic or $2^{\prime} \mathrm{Nal}$, or upon replacement of $\mathrm{Phe}^{4}$ by Dmt. ${ }^{13}$ When both $\mathrm{Tyr}^{1}$ and $\mathrm{Phe}^{4}$ were substituted, as for compounds 7 (Ac- $\left[\mathrm{Dmt}^{1}, \mathrm{Dmt}^{4}\right]$-NMU-8), 8 (Ac-[7-OH$\left.\mathrm{Tic}^{1}, 2^{\prime} \mathrm{Nal}^{4}\right]-\mathrm{NMU}-8$ ), and $\mathbf{1 0}$ (Ac-[7-OH-Tic $\left.{ }^{1}, \mathrm{Dap}^{4}\right]-\mathrm{NMU}$ $8)$, two major cleavage sites were found more precisely, in the middle of the sequence and between $\operatorname{Arg}^{7}-\mathrm{Asn}^{8}$ (Figure 4). For NMU-analogs 7 and 8, the major degradation site was found to be in the middle of the NMU-sequence, between the modified $\mathrm{Phe}^{4}$ residue and $\mathrm{Arg}^{5}$, resulting in plasma half-lifes of $201.5 \pm$ $6.3 \mathrm{~min}$ and $142.3 \pm 1.3 \mathrm{~min}$ for 7 and 8 , respectively. To a smaller extent, the peptides were cleaved between $\mathrm{Arg}^{7}-\mathrm{Asn}^{8}$. These degradation profiles indicate that unnatural amino acids such as Dmt and $2^{\prime} \mathrm{Nal}$ are able to suppress, but not eliminate, hydrolysis of the adjacent amide bonds. When the backbone amide of the Phe residue in position 4 was modified, as in the case of compound 10 where $\mathrm{Phe}^{4}$ was replaced by $\mathrm{NMePhe}$, the priority of the biodegradation sites switched to $\mathrm{Arg}^{7}-\mathrm{Asn}^{8}$ as the major cleavage site (see Supporting Information, Table S4 and Figure S5). The scissile $\mathrm{Phe}^{4}-\mathrm{Arg}^{5}$ amide bond was protected by the introduction of a methyl group on the backbone amide and was only cleaved to a minor extent, resulting in a prolonged half-life of $1804.2 \pm 77.5 \mathrm{~min}$ ( or $30.1 \pm 1.3 \mathrm{~h}$ ). Again, this observation indicates that $\mathrm{N}$-alkylation of the amide bond between $\mathrm{Phe}^{4}$ and $\mathrm{Arg}^{5}$ seems a promising avenue toward extremely stable hNMUR1 agonists.

$$
\begin{array}{l|c}
A C-A A_{1}-A A_{2}-A A_{3}-A A_{4}-A A_{5}-A A_{6}-A A_{7}-A A_{8}-N H_{2} & \text { Compounds } \\
\text { AC }-A A_{1}-A A_{2}-A A_{3}-A A_{4}-A A_{5}-A A_{6}-A A_{7}-A A_{8}-N H_{2} & 1 \\
A C-A A_{1}-A A_{2}-A A_{3}-A A_{4}-A A_{5}-A A_{6}-A A_{7}-A A_{8}-N H_{2} & 2,3 \\
A C-A A_{1}-A A_{2}-A_{3}-A A_{4}-A A_{5}-A A_{6}-A A_{7}-A A_{8}-N H_{2} & 7,8,10
\end{array}
$$

Figure 4. Schematic representation of the biodegradation profiles of the novel NMU-analogs. Colored amino acid positions (AA) indicate where modifications are introduced (cfr. Figure 1). The major cleavage sites are indicated with dotted lines.

In conclusion, the present study proves that modifications in the $C$-terminal region, previously reported as the critical segment, of the NMU-8 sequence are tolerated. Moreover, the substitution of the $\operatorname{Arg}^{7}$ by $\beta^{3}$ hArg increased the resistance against proteolytic degradation resulting in a half-life of more than $19 \mathrm{~h}$ in human plasma. Importantly, we synthesized a series of NMU-analogs with an increased selectivity for NMUR1. The novel NMU-derivative 7 possesses subnanomolar affinity for the receptor and a 10 -fold increased potency as compared to NMU-8, together with an $18 \%$ higher $E_{\max }$. No significant NMUR2 receptor activation was found up to $10^{-6}$ M. Moreover, a more than 50-fold extension of the plasma halflife was observed for compound 7 . When modifications were introduced in the backbone, as for analog 10, a plasma half-life up to $30 \mathrm{~h}$ was found. In general, stabilization of the $\mathrm{Phe}^{4}-\mathrm{Arg}^{5}$ bond is necessary for obtaining NMU-8 analogs with prolonged plasma stability. We are convinced that potent and proteolyti- cally stable NMUR1 agonists, such as the ones reported in this report, could serve as useful tools for further elucidating the role of this receptor in NMU signaling, which seems to be involved in feeding behavior and glucose tolerance. ${ }^{3,18}$ Moreover, NMUR1 is recently gaining a lot of attention since it seems to play a role in type 2 lymphoid driven inflammation and allergic lung inflammation. ${ }^{19-21}$

\section{ASSOCIATED CONTENT}

\section{Supporting Information}

The Supporting Information is available free of charge on the ACS Publications website at DOI: 10.1021/acsmedchemlett.8b00105.

Experimental procedures along with peptide characterization data (PDF)

\section{AUTHOR INFORMATION}

\section{Corresponding Authors}

*Tel: 0032-2-6293292. E-mail: steven.ballet@vub.be.

*Tel: 0032-2-4774747. E-mail: ilse.smolders@vub.be.

*Tel: 0045-30604608. E-mail: rosenkilde@sund.ku.dk.

ORCID $\odot$

Steven Ballet: 0000-0003-4123-1641

\section{Author Contributions}

ADP synthesized the ligands, performed the experiments, and wrote the paper. CM assisted with the identification of the metabolites and YVW with the plasma stability assay. CT provided the $\left[{ }^{3} \mathrm{H}\right]-\mathrm{NMU}-8$ peptide. VC helped revise the manuscript. DT contributed to confine the synthesis strategy. $\mathrm{BH}$ and MMR supervised the in vitro activity and binding assays. AVE supervised the stability study. IS and SB supervised and designed the research study. All authors have given approval to the final version of the manuscript.

\section{Notes}

The authors declare no competing financial interest.

\section{ACKNOWLEDGMENTS}

ADP was supported by the Flanders Innovation \& Entrepreneurship Agency (VLAIO) and the Research Foundation Flanders (FWO). The authors thank the Research Council (OZR) of the Vrije Universiteit Brussel for funding through the Strategic Research Program and the Queen Elisabeth Medical Foundation (G.S.K.E - 2017-2019) for the financial support.

\section{ABBREVIATIONS}

$2^{\prime} \mathrm{Nal}, 2$-naphtylalanine; 7-OH-Tic, 7-hydroxy-L-1,2,3,4-tetrahydroisoquinoline-3-carboxylic acid; Atc, (D,L)-2-aminotetraline-2-carboxylic acid; Dap, $\alpha, \beta$-diaminoropionic acid; DIPEA, diethyldothiocarbamate; Dmt, 7-hydroxy-L-1,2,3,4-tetrahydroisoquinoline-3-carboxylic acid; Fmoc, 9-fluorenylmethyloxycarbonyl; HEK293, human embryonic kidney 293; HPLC, high performance liquid chromatography; HRMS, high resolution mass spectrometry; $\mathrm{IP}_{3}$, inositol triphosphate; NMU, Neuromedin U; NMUR, Neuromedin U receptor; TES, triethylsilane; TFA, trifluoroacetic acid; TBTU, 2-(1H-benzotriazole-1-yl)1,1,3,3-tetramethylaminium tetrafluoroborate; $\beta^{3} \mathrm{hArg}$, $\beta^{3}$ homoarginine 


\section{REFERENCES}

(1) Brighton, P. J.; Szekeres, P. G.; Willars, G. B. Neuromedin U and its receptors: structure, function, and physiological roles. Pharmacol. Rev. 2004, 56 (2), 231-48.

(2) Mitchell, J. D.; Maguire, J. J.; Davenport, A. P. Emerging pharmacology and physiology of neuromedin $U$ and the structurally related peptide neuromedin S. Br. J. Pharmacol. 2009, 158 (1), 87103.

(3) Peier, A. M.; Desai, K.; Hubert, J.; Du, X.; Yang, L.; Qian, Y.; Kosinski, J. R.; Metzger, J. M.; Pocai, A.; Nawrocki, A. R.; Langdon, R. B.; Marsh, D. J. Effects of peripherally administered neuromedin $U$ on energy and glucose homeostasis. Endocrinology 2011, 152 (7), 264454.

(4) Takayama, K.; Mori, K.; Taketa, K.; Taguchi, A.; Yakushiji, F.; Minamino, N.; Miyazato, M.; Kangawa, K.; Hayashi, Y. Discovery of selective hexapeptide agonists to human neuromedin $U$ receptors types 1 and 2. J. Med. Chem. 2014, 57 (15), 6583-93.

(5) Takayama, K.; Mori, K.; Tanaka, A.; Nomura, E.; Sohma, Y.; Mori, M.; Taguchi, A.; Taniguchi, A.; Sakane, T.; Yamamoto, A.; Minamino, N.; Miyazato, M.; Kangawa, K.; Hayashi, Y. Discovery of a Human Neuromedin U Receptor 1-Selective Hexapeptide Agonist with Enhanced Serum Stability. J. Med. Chem. 2017, 60 (12), 52285234.

(6) Micewicz, E. D.; Bahattab, O. S.; Willars, G. B.; Waring, A. J.; Navab, M.; Whitelegge, J. P.; McBride, W. H.; Ruchala, P. Small lipidated anti-obesity compounds derived from neuromedin U. Eur. J. Med. Chem. 2015, 101, 616-26.

(7) Dalboge, L. S.; Pedersen, S. L.; van Witteloostuijn, S. B.; Rasmussen, J. E.; Rigbolt, K. T.; Jensen, K. J.; Holst, B.; Vrang, N.; Jelsing, J. Synthesis and evaluation of novel lipidated neuromedin U analogs with increased stability and effects on food intake. J. Pept. Sci. 2015, 21 (2), 85-94.

(8) Ingallinella, P.; Peier, A. M.; Pocai, A.; Marco, A. D.; Desai, K.; Zytko, K.; Qian, Y.; Du, X.; Cellucci, A.; Monteagudo, E.; Laufer, R.; Bianchi, E.; Marsh, D. J.; Pessi, A. PEGylation of Neuromedin U yields a promising candidate for the treatment of obesity and diabetes. Bioorg. Med. Chem. 2012, 20 (15), 4751-9.

(9) Neuner, P.; Peier, A. M.; Talamo, F.; Ingallinella, P.; Lahm, A.; Barbato, G.; Di Marco, A.; Desai, K.; Zytko, K.; Qian, Y.; Du, X.; Ricci, D.; Monteagudo, E.; Laufer, R.; Pocai, A.; Bianchi, E.; Marsh, D. J.; Pessi, A. Development of a neuromedin U-human serum albumin conjugate as a long-acting candidate for the treatment of obesity and diabetes. Comparison with the PEGylated peptide. J. Pept. Sci. 2014, 20 (1), 7-19.

(10) Inooka, H.; Sakamoto, K.; Shinohara, T.; Masuda, Y.; Terada, M.; Kumano, S.; Yokoyama, K.; Noguchi, J.; Nishizawa, N.; Kamiguchi, H.; Fujita, H.; Asami, T.; Takekawa, S.; Ohtaki, T. A PEGylated analog of short-length Neuromedin $U$ with potent anorectic and anti-obesity effects. Bioorg. Med. Chem. 2017, 25 (8), 2307-2312.

(11) Kanematsu-Yamaki, Y.; Nishizawa, N.; Kaisho, T.; Nagai, H.; Mochida, T.; Asakawa, T.; Inooka, H.; Dote, K.; Fujita, H.; Matsumiya, K.; Hirabayashi, H.; Sakamoto, J.; Ohtaki, T.; Takekawa, S.; Asami, T. Potent Body Weight-Lowering Effect of a Neuromedin U Receptor 2selective PEGylated Peptide. J. Med. Chem. 2017, 60 (14), 6089-6097. (12) Nishizawa, N.; Kanematsu-Yamaki, Y.; Funata, M.; Nagai, H.; Shimizu, A.; Fujita, H.; Sakamoto, J.; Takekawa, S.; Asami, T. A potent neuromedin $\mathrm{U}$ receptor 2-selective alkylated peptide. Bioorg. Med. Chem. Lett. 2017, 27 (20), 4626-4629.

(13) De Prins, A.; Martin, C.; Van Wanseele, Y.; Skov, L. J.; Tomboly, C.; Tourwe, D.; Caveliers, V.; Van Eeckhaut, A.; Holst, B.; Rosenkilde, M. M.; Smolders, I.; Ballet, S. Development of potent and proteolytically stable human neuromedin U receptor agonists. Eur. J. Med. Chem. 2018, 144, 887-897.

(14) Murphy, J. E.; Uno, T.; Hamer, J. D.; Cohen, F. E.; Dwarki, V.; Zuckermann, R. N. A combinatorial approach to the discovery of efficient cationic peptoid reagents for gene delivery. Proc. Natl. Acad. Sci. U. S. A. 1998, 95 (4), 1517-22.
(15) Rink, R.; Arkema-Meter, A.; Baudoin, I.; Post, E.; Kuipers, A.; Nelemans, S. A.; Akanbi, M. H.; Moll, G. N. To protect peptide pharmaceuticals against peptidases. J. Pharmacol. Toxicol. Methods 2010, 61 (2), 210-8.

(16) Crisma, M.; Bonora, G. M.; Toniolo, C.; Barone, V.; Benedetti, E.; Di Blasio, B.; Pavone, V.; Pedone, C.; Santini, A.; Fraternali, F.; et al. Structural versatility of peptides containing $\mathrm{C}$ alpha, alphadialkylated glycines: conformational energy computations, i.r. absorption and $1 \mathrm{H}$ n.m.r. analysis of 1 -aminocyclopropane-1carboxylic acid homopeptides. Int. J. Biol. Macromol. 1989, 11 (6), 345-52.

(17) Arduin, M.; Spagnolo, B.; Calo, G.; Guerrini, R.; Carra, G.; Fischetti, C.; Trapella, C.; Marzola, E.; McDonald, J.; Lambert, D. G.; Regoli, D.; Salvadori, S. Synthesis and biological activity of nociceptin/ orphanin FQ analogues substituted in position 7 or 11 with Calpha,alpha-dialkylated amino acids. Bioorg. Med. Chem. 2007, 15 (13), 4434-43.

(18) Martinez, V. G.; O’Driscoll, L. Neuromedin U: a multifunctional neuropeptide with pleiotropic roles. Clin. Chem. 2015, 61 (3), 471-82.

(19) Cardoso, V.; Chesne, J.; Ribeiro, H.; Garcia-Cassani, B.; Carvalho, T.; Bouchery, T.; Shah, K.; Barbosa-Morais, N. L.; Harris, $\mathrm{N}$.; Veiga-Fernandes, H. Neuronal regulation of type 2 innate lymphoid cells via neuromedin U. Nature 2017, 549 (7671), 277-281.

(20) Klose, C. S. N.; Mahlakoiv, T.; Moeller, J. B.; Rankin, L. C.; Flamar, A. L.; Kabata, H.; Monticelli, L. A.; Moriyama, S.; Putzel, G. G.; Rakhilin, N.; Shen, X.; Kostenis, E.; Konig, G. M.; Senda, T.; Carpenter, D.; Farber, D. L.; Artis, D. The neuropeptide neuromedin $\mathrm{U}$ stimulates innate lymphoid cells and type 2 inflammation. Nature 2017, 549 (7671), 282-286.

(21) Wallrapp, A.; Riesenfeld, S. J.; Burkett, P. R.; Abdulnour, R. E.; Nyman, J.; Dionne, D.; Hofree, M.; Cuoco, M. S.; Rodman, C.; Farouq, D.; Haas, B. J.; Tickle, T. L.; Trombetta, J. J.; Baral, P.; Klose, C. S. N.; Mahlakoiv, T.; Artis, D.; Rozenblatt-Rosen, O.; Chiu, I. M.; Levy, B. D.; Kowalczyk, M. S.; Regev, A.; Kuchroo, V. K. The neuropeptide NMU amplifies ILC2-driven allergic lung inflammation. Nature 2017, 549 (7672), 351-356. 